\title{
Triple negative phenomenon in endometrial cancer: recognition criteria and impact on survival
}

\author{
Michal Bulsa®, Elzbieta Urasinska®i) \\ Department of Pathology, Pomeranian Medical University, Szczecin, Poland
}

\begin{abstract}
Objectives: Endometrial cancer is the most common malignant cancer of female reproductive organs. The number of diagnosed cases of endometrial cancer is increasing from year to year. Endometrial cancer is a neoplasm with a good survival rate. However, there are also cases with a fast, aggressive course. In recent years, the triple negative phenomenon (TNP) has been identified as one of the factors determining shorter survival in patients with endometrial cancer. Material and methods: The study covered 265 patients with histopathologically confirmed endometrial cancer. Patients were divided into two groups: 1) patients with endometrial cancer with TNP; 2) patients with endometrial cancer without TNP. Tissue microarrays (TMA) were examined with immunohistochemistry to evaluate the expression of estrogen, progesterone and HER2 receptors. In several cases FISH method was used to assess HER2. The expression was evaluated by computer image analysis using the Nuclear Image Analysis virtual microscopy system. The evaluation of HER2 expression was performed manually. The criterion for TNC diagnosis was H-Score $<50$ or $<75$ and Allred score $<4$.

Results: Depending on the scoring system used, TNP was found in from $10.19 \%$ to $15.09 \%$ of cases. Regardless of the criteria employed in endometrial cancer, the presence of TNP was neither a factor increasing the risk of death nor it affected the patients' survival.

Conclusions: The proportion of TNP diagnosed in endometrial cancer depends on the examined population and the diagnostic criteria. The incidence of TNP did not affect the survival of patients.

Key words: endometrial cancer; triple negative endometrial cancer; triple negative cancer; H-Score; Allred Score; triple negative phenomenon
\end{abstract}

Ginekologia Polska 2022; 93, 2: 91-98

\section{INTRODUCTION}

Endometrial cancer is the most common female genital cancer in the developed countries [1]. According to the WHO (World Health Organization) report, the number of reported new cases of endometrial cancer was 327,259 in 2018, an increase of 7,659 new cases compared to the previous report published in 2012 [2].

Similarly, to the estrogen receptor (ER), the positive expression of progesterone receptor (PR) is associated with increased survival in endometrial carcinoma [3, 4]. In 2013, a multicentre study was conducted which showed reduced survival in women with endometrial cancer in the absence of PR and ER expression [5]. The lack of PR expression is also associated with a higher risk of relapse of the neoplastic process [6]. The degree of ER expression is considered as an independent prognostic factor. Reduced survival in endometrial cancer patients occurred in the absence of ERa expression [7]. Patients showing no ERa expression were diagnosed with higher neoplastic grading and higher stage of neoplastic progression [8].

The amplification of the HER2 gene, which results in an increased amount of HER2 protein, is characteristic of the second type of endometrial cancer, the so called non-estrogen-dependent endometrial cancer. This concerns about 17-30\% of cases [9]. It was found that endometrial cancers with positive expression of HER2 receptor have a more aggressive clinical course [10]. Although HER2 gene amplification is characteristic for type II endometrial cancers, some authors confirm the fact that HER2 positive expression is a prognostic factor for type I endometrial cancers [11, 12].

The triple negative phenomenon (TNP) was first described in association with breast cancer. TNP means the lack of ER, PR and HER2 expressions in neoplastic tissue. As regards breast cancer, the triple negative phenomenon 
has been thoroughly investigated. Triple negative cancers (TNCs) represent about $10-20 \%$ of all breast cancers and lead to worse outcomes. The authors of the study cited above suggest a better prognostic value of HER-2 overexpression than that of PTEN [13].

It was not until 2010 that TNP was described in reference to a cancer different than breast cancer. It was found that the percentage rate of endometrial TNCs was $26 \%$. They were at a more severe clinical stage at the time of diagnosis and were accompanied by the presence of lymph node metastases, deeper uterine infiltration and an unfavourable histopathological type, i.e., clear-cell or serous carcinoma. There is a limited number of reports of triple negative endometrial cancer [14-19].

\section{Objectives}

The purpose of this study was to assess the percentage of endometrial carcinomas with TNP and the survival odds for patients with endometrial cancer with TNP.

\section{MATERIAL AND METHODS}

The study group consisted of 265 women with histopathologically confirmed diagnosis of endometrial cancer who underwent surgery between 2004 and 2016.

The patients were divided into two groups:

1. Patients with endometrial cancer with TNP

2. Patients with endometrial cancer without TNP

The observations were terminated on 9 October 2018. On the last day of the observation, the total of 53 patients was reported to have died. In 26 cases it was not possible to obtain information concerning the exact date of death. Data on patients' deaths were collected from the register of deaths run by Department of State Systems of the Polish Ministry of Digitization.

For the purpose of prognosis assessment, the overall survival (OS) was defined as the time from surgery to the end of observation or to the patient's death.

The research project received a favourable opinion by the Bioethical Commission of the Pomeranian Medical University in Szczecin no. KB-0012/01/01/2015 of 07 January 2015.

The description of the study group is shown in Table 1.

The study was conducted on tissue microarrays (TMA) made of paraffin blocks including material retrieved for the purpose of routine histopathological tests from post-surgery preparations fixed in $10 \%$ formalin solution and embedded in paraffin. TMA is a multi-stage technique. First, the representative locations were selected from the original histopathological specimen stained with haematoxylin and eosin. There were three representative locations of tumour metastasis. In the second stage cylindrical tissue samples of $0.6 \mathrm{~mm}$ in diameter were extracted from the places in the donor paraffin block that correspond to the places marked in the histopathological preparation and placed in the pre-drilled recipient block. Subsequently, the recipient block was embedded in paraffin. In the final stage, the block was cut into 4- $\mu \mathrm{m}$-thin segments that are subject to immunohistochemical examination or to fluorescent in situ hybridization (FISH) $[20,21]$. A large number of fragments of various preparations in one recipient block formed a map representing a position of each preparation. The array of these fragments in the recipient block needed to be precisely spaced so that each sample can be unambiguously identifiable.

In this study the immunohistochemical protocol was used to assess the expression of ER and PR. The process of immunohistochemical staining by means of the EnVision $^{\mathrm{TM}}$ FLEX Dako set consisted of several consecutive stages. First, the slides obtained from the paraffin blocks with the microarrayed tissue was deparaffinised for 60 minutes in a dry oven at $58^{\circ} \mathrm{C}$. Then the antigen was deparaffinized by hydrothermal pressure at $120^{\circ} \mathrm{C}$ with the retrieval buffer

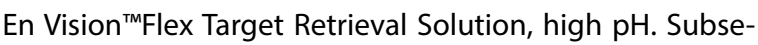
quently, the endogenous peroxidase was blocked for five minutes by means of En Vision ${ }^{\mathrm{TM} F l e x}$ Peroxidase-Blocking Reagent. For another five minutes the slides were immersed in the (En Vision ${ }^{\text {TM}}$ Flex Wash Buffer). In the following stage the slides were incubated with primary antibody. The used antibodies were anti-estrogen receptor (clone 1D5, 1:50 solution, Dako) and anti-progesterone receptor (clone PgR $636,1: 50$ solution; Dako). The incubation time was $20 \mathrm{~min}$ utes. Next, the slides were immersed in the buffer for another five minutes followed by 20-minute incubation with the polymer (EnVisionTM FLEX /HRP). The last buffer wash took five minutes. Then the staining procedure with EnVisionTM FLEX DAB+ Chromogen took place for 10 minutes followed by a 10-minute bath in de-ionized water. One of the last stages was the immersion in haematoxylin staining (EnVisionTMFLEX Hematoxylin) for another 10 minutes, followed by 10 minutes of washing the slides in tap water. Finally, the slides were dehydrated by immersing the slides in several isopropyl alcohols of strength growing gradually from $70 \%$ to $98 \%$ and in several xylene solutions of varying concentration. In the last step, the slide was protected with a coverslip and a commercial antifading mountant (Dako Mounting Medium).

HER-2 expression was tested with HercepTest (Dako). With HER-2 expression value at $2+$, an additional staining of FISH was performed in order to determine the HER-2 gene amplification. FISH is performed in several stages. It starts with cutting the paraffin block into $4-5 \mu \mathrm{m}$ thin segments that are mounted on microscope slides. In this study the test was performed according to a standard HER-2-dedicated FISH protocol recommended by the manufacturer. The LSI 


\begin{tabular}{|c|c|c|c|c|}
\hline \multicolumn{2}{|l|}{ Parameters under evaluation } & $\mathbf{N}$ & Number & $\%$ \\
\hline \multirow{3}{*}{ Age at time of cancer diagnosis } & Mean & \multirow{3}{*}{265} & 63.21 & - \\
\hline & SD & & 9.73 & - \\
\hline & Median & & 62 & - \\
\hline \multirow{7}{*}{ FIGO and WHO histological type } & Endometrioid carcinoma & \multirow{7}{*}{265} & 254 & 95.85 \\
\hline & Mucosal carcinoma & & 0 & 0 \\
\hline & Serous carcinoma & & 4 & 1.51 \\
\hline & Clear-cell carcinoma & & 3 & 1.13 \\
\hline & Neuroendocrine neoplasm & & 1 & 0.38 \\
\hline & Mixed-cell adenocarcinoma & & 1 & 0.38 \\
\hline & Undifferentiated carcinoma & & 2 & 0.75 \\
\hline \multirow{3}{*}{ Grading } & G1 & \multirow{3}{*}{265} & 144 & 54.34 \\
\hline & G2 & & 92 & 34.72 \\
\hline & G3 & & 29 & 10.94 \\
\hline \multirow{9}{*}{ FIGO clinical stage } & IA & \multirow{9}{*}{265} & 155 & 58.49 \\
\hline & IB & & 68 & 25.66 \\
\hline & ॥ & & 24 & 9.06 \\
\hline & IIIA & & 15 & 5.66 \\
\hline & IIIB & & 0 & 0 \\
\hline & IIIC 1 & & 1 & 0.38 \\
\hline & IIIC 2 & & 0 & 0 \\
\hline & IVA & & 1 & 0.38 \\
\hline & IVB & & 1 & 0.38 \\
\hline \multirow{5}{*}{ BMI } & $<25,0$ normal weight & \multirow{5}{*}{240} & 47 & 19.58 \\
\hline & (25-29.99) overweight & & 71 & 29.58 \\
\hline & $(30-34,99) 1^{0}$ obesity & & 68 & 28.33 \\
\hline & $(35-39,99) 2^{0}$ obesity & & 34 & 14.17 \\
\hline & $(>40) 3^{0}$ obesity & & 20 & 8.33 \\
\hline \multirow{2}{*}{ Hypertension } & Absent & \multirow{2}{*}{256} & 96 & 37.5 \\
\hline & Present & & 160 & 62.5 \\
\hline \multirow{2}{*}{ Type II diabetes mellitus } & Absent & \multirow{2}{*}{256} & 203 & 78.9 \\
\hline & Present & & 53 & 21.1 \\
\hline
\end{tabular}

SD — standard deviation; FIGO — International Federation of Gynecology and Obstetrics; WHO — World Health Organization

HER-2/neu and CEP17 probes from PathVysion HER-2 DNA Probe Kit (Abbott Laboratories) were used. Fluorescent in situ hybridisation is a technique where tissue is treated with proteolytic enzymes (here: proteinase K) in order to destroy proteins constituting the cell membrane. Tissue is covered with the DNA probe solution being a mixture of two molecular probes. The HER-2/neu (LSI - Locus Specific Identifier) probe, which is rendered orange with fluorochrome, binds to the HER-2 gene sequence while the second probe (CEP - Chromosome Enumeration Probe), rendered green, binds to the complementary area of chromosome 17 centromer. The samples were then denaturised and hybridized. Cell nuclei were identified by means of DAPI stain. The hybridisation effects were assessed under the fluorescence microscope. The relation between LSI (HER2/neu) probe and CEP17 probe was quantified by the so called HER2/CEP17 ratio.

The $\mathrm{H}$-Score is a semi-quantitative method for assessing the intensity of protein or receptor expression and the quantity of cells indicating individual degrees of expression. The score gives a range from 0 to 300 . In case of the $\mathrm{H}$-Score two cut-off values were used based on literature data. According to McCarty et al. [22], the ER expression is regarded positive when the $\mathrm{H}$-Score is equal to and higher than 75. McCarty et al., criteria were also used by other authors [23]. However, according to Thinke et al. [24], the H-Score below 50 is con- 
Table 2. Criteria for TNP diagnosis

\begin{tabular}{|l|c|c|}
\hline Grading scale & Receptor negative expression criterion & Criteria for TNC diagnosis \\
\hline H-Score & $\leq 50$ & PR and ER $\leq 50$ by H-Score and rec. HER-2 negative \\
\hline H-Score & $\leq 75$ & PR and ER $\leq 75$ by H-Score and rec. HER-2 negative \\
\hline Allred & $\leq 4$ & PR and ER $\leq 4$ by Allreda and rec. HER-2 negative \\
\hline
\end{tabular}

TNC — triple negative cancer; PR — progesterone receptor; ER — estrogen receptor

sidered negative for ER or PR expression. It is noteworthy that a threshold below 75 was described in the studies on breast cancer and endometrial cancer, as opposed to a threshold below 50 which was described solely for breast cancer [22-24]. Therefore, two cut-off values of the negative ER and PR expression were adopted for the H-Score: below 50 and below 75 .

The eight-grade score by Allred et al. [25], was also used to identify ER and PR expressions. The score from 0 to 6 was used to describe the proportion of tumour cells showing positive nuclear staining $-\mathrm{A}(0=$ none; $1 \leq 1 \%$; $2=2-9 \% ; 3=10-33 \% ; 4=34 \_66 \% ; 5>66 \%$ ) while the score from $0-4$ represented the staining intensity $-B(0=$ none; $1=$ weak $; 2=$ moderate; 3 =strong). The result was described as the sum of $A+B=T S$ (Total Score). The original system used by Allred distinguished two categories: no expression when TS equalled 0-2 points, and positive expression at TS between 3-8 points. Regarding endometrial cancer, Gottwald et al., used modified TS scales for the Allred score. They assumed that for a score of 0 points - no expression was found; at 2-4 points the expression was considered weak, while at 5-8 points the expression was seen as strong [26]. Given the literature data on the percentage of endometrial cancers showing TNP, the following interpretation was adopted for the purpose of this study: the number of points equal to or below 4 - no expression of ER and PR, while the points above $4-$ a positive expression.

The HER2 expression was interpreted according to standard criteria. In the absence of recommendations concerning HER2 determination in endometrial cancers, the recommendations for interpreting HER2 test results for breast carcinomas were followed [27]. In cases of doubt (HER-2 was at the level of 2+), FISH was performed with the purpose of determining the number of gene copies. Depending on the scale used to assess PR and ER expression, the criteria outlined in Table 2 were adopted for diagnosing the triple negative phenomenon.

The tissue microarray preparation was scanned with Aperio Cs scanner. The proportion of cells showing a positive response was evaluated using computer image analysis by means of the Nuclear Image Analysis virtual microscopy system. The process was made possible due to the application of algorithms (Image Score Version 11.2.0.780) evaluating the intensity of immunohistochemical reactions

\begin{tabular}{|l|c|c|}
\hline \multicolumn{3}{|l|}{ Table 3. Percentage of TNC by type of scale } \\
\hline & Number & $\%$ \\
\hline TNC at H-SCORE $<75$ & & \\
\hline Absent & 225 & 84.91 \\
\hline Present & 40 & 15.09 \\
\hline TNC at H-SCORE $<50$ & & \\
\hline Absent & 236 & 89.06 \\
\hline Present & 29 & 10.94 \\
\hline TNC at Allred Score & & \\
\hline Absent & 238 & 89.81 \\
\hline Present & 27 & 10.19 \\
\hline
\end{tabular}

TNC — triple negative cancer

and their number. The evaluation of HER2 expressions was done manually.

The normality of distributions of all variables was checked by Kolmogorov-Smirnov test. The statistical relationships between discontinuous variables were examined using Pearson's $X 2$ test. The survival analysis was employed to assess the overall survival. The results were presented with Kaplan-Meier curves. In order to decide which factors increased the survival odds, the Cox regression model was used. The results were described with HR (Hazard Ratio) with $95 \%$ confidence interval and probability. The differences were considered statistically significant when their probability was lower than 0.05 .

\section{RESULTS}

Depending on the score system used, TNP was found in $10.19-15.09 \%$ of cases. The results are listed in Table 3. Depending on the criteria adopted for the diagnosis, the proportion of deaths varied from $25.71 \%$ to $29.17 \%$ of patients with TNC. Although there were discrepancies in the death rates of patients with and without TNP, no statistically significant differences were found. The proportions of deaths by the criteria adopted for the TNP diagnosis are outlined in Table 4. In the next stage of the study, the analysis of survival was performed using Kaplan-Meier curves in relation to the TNP incidence, depending on the applied diagnosis criterion. The results are givenin figures $1-3$. Further analysis by the Cox regression method failed to provide the answer whether TNP was or was not a risk factor leading to the death of patients, regardless of 


\begin{tabular}{|c|c|c|c|c|c|}
\hline \multicolumn{6}{|c|}{ Endometrial carcinoma (whole population under study) } \\
\hline & \multicolumn{2}{|c|}{ Death - } & \multicolumn{2}{|c|}{ Death +} & \multirow[t]{2}{*}{$\mathbf{p}$} \\
\hline TNP by & & & & & \\
\hline Absent & 160 & $78.43 \%$ & 44 & $21.57 \%$ & 0.58545 \\
\hline Present & 26 & $74.29 \%$ & 9 & $25.71 \%$ & \\
\hline \multicolumn{6}{|c|}{ TNP by H-Score $<50$} \\
\hline absent & 169 & $78.60 \%$ & 46 & $21.40 \%$ & 0.38474 \\
\hline present & 17 & $70.83 \%$ & 7 & $29.17 \%$ & \\
\hline \multicolumn{6}{|c|}{ TNP by Allred Score } \\
\hline absent & 169 & $78.24 \%$ & 47 & $21.76 \%$ & 0.63482 \\
\hline present & 17 & 73.91\% & 6 & $26.09 \%$ & \\
\hline
\end{tabular}

TNP — triple negative phenomenon the adopted diagnostic scoring system. The results are given in Table 5. The presence of TNP, irrespective of the criteria applied in endometrial cancer, was neither a factor increasing the risk of death nor it affected the patients' survival.

\section{DISCUSSION}

The studies describing TNP in endometrial cancer are scarce. Three research teams adopted the following criteria for determining the ER and PR status: the expression at the level $3+$ was assumed to be the strong or weak expression of $50 \%$ or more of all cells, while the expression at the level $2+$ was assumed to be the strong or weak expression in the range of $\geq 50 \%$ and $\leq 10 \%$ of all cells. The results classified as $1+$ or 0 were considered negative, whereas $1+$ meant strong or weak expression of less than $10 \%$ of all cells.

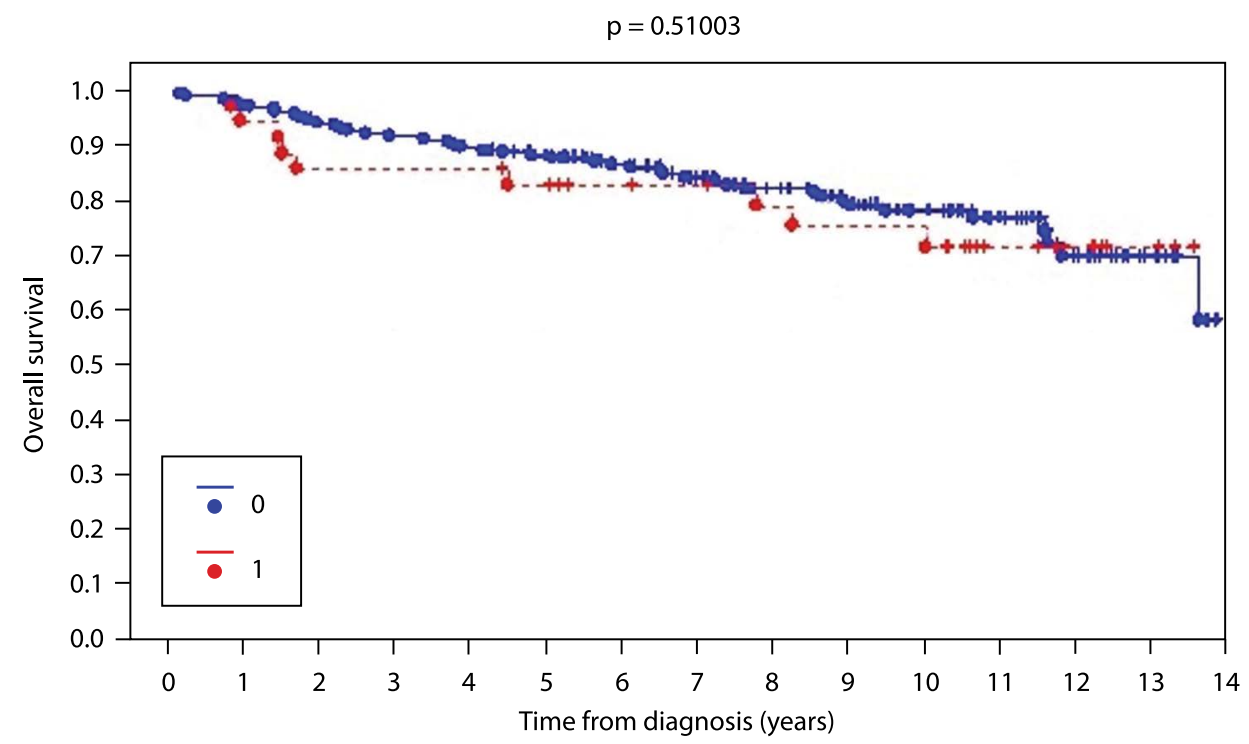

Figure 1. Kaplan-Meier survival curve in relation to TNP presence according to criteria of $\mathrm{H}$-Score $<75 ; 0-$ absent; 1 - present

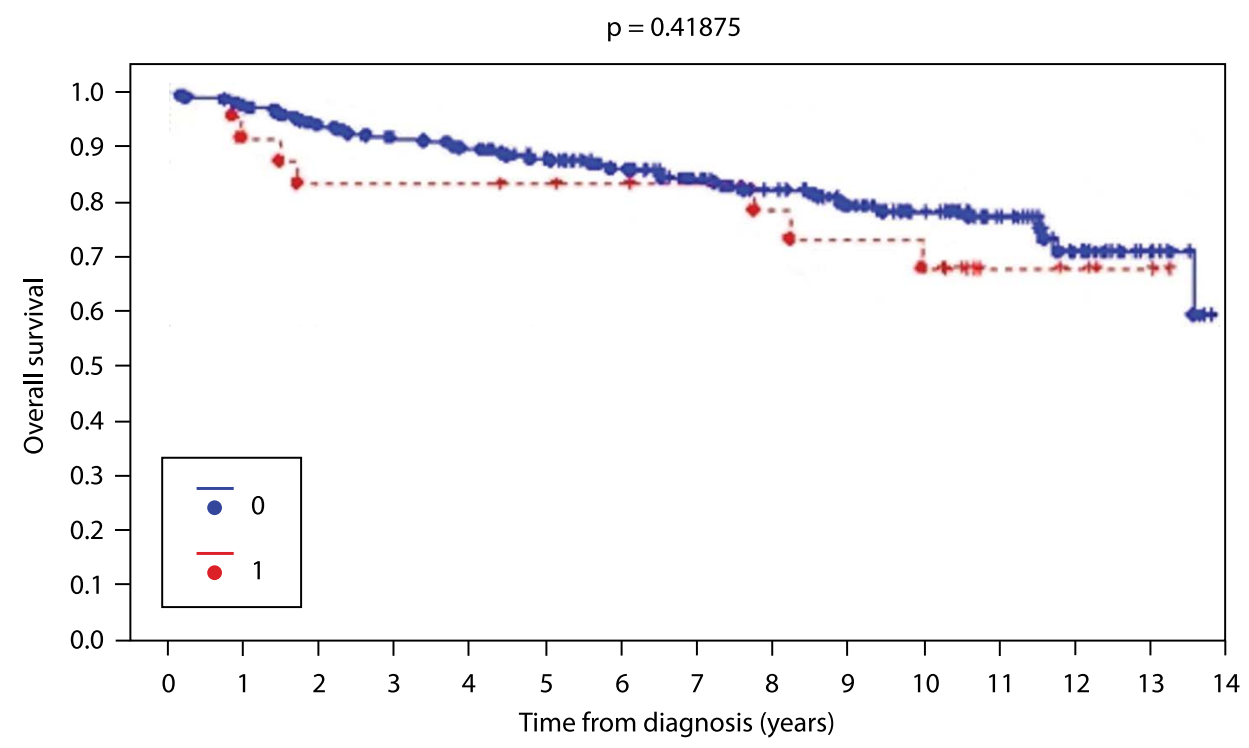

Figure 2. Kaplan-Meier survival curve in relation to TNP presence according to criteria of $\mathrm{H}$-Score $<50 ; 0$-- absent; 1 -- present 


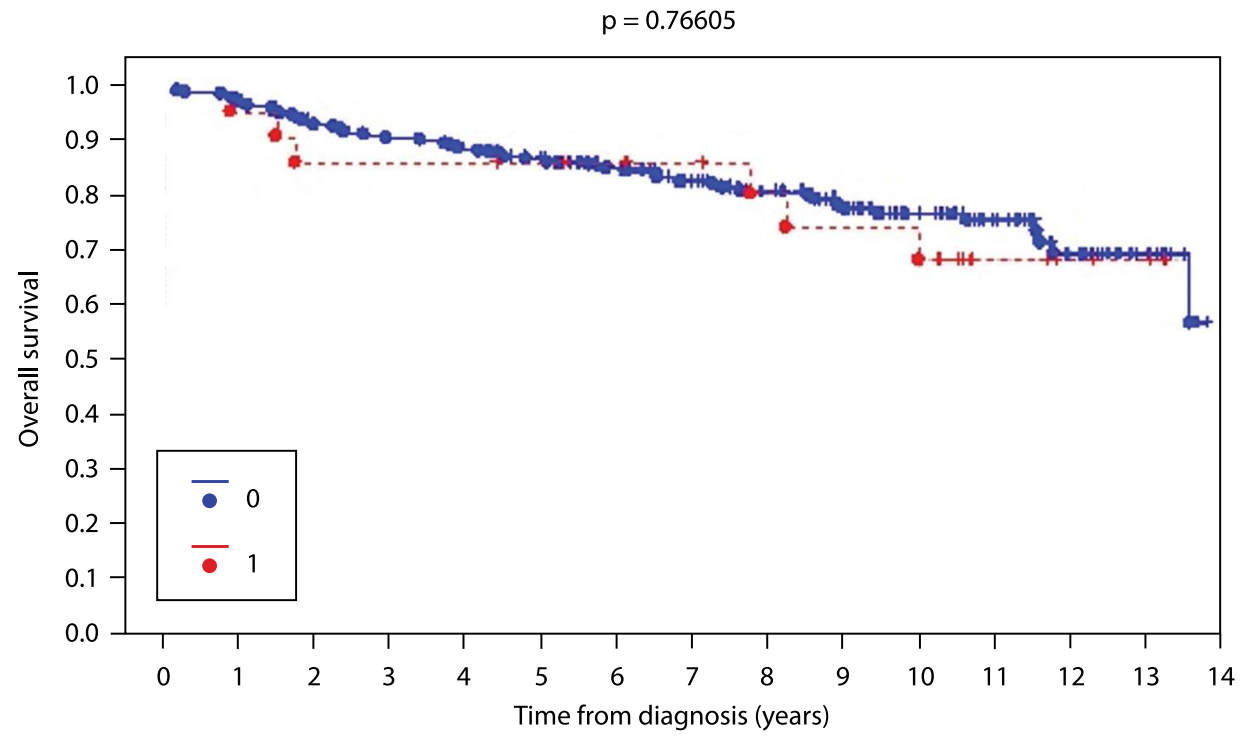

Figure 3. Kaplan-Meier survival curve in relation to TNP presence according to criterion of Alfred score; 0 -- absent; 1 -- present

\begin{tabular}{|l|c|c|c|c|}
\hline \multicolumn{6}{|l|}{ Table 5. TNP - death risk factor - Cox regression analysis } \\
\hline Risk factors & HZ & $95 \%$ & Cl & p \\
\hline Incidence of TNP by H-Score $<75$ & 1.10 & 0.54 & 2.27 & 0.787 \\
\hline Incidence of TNP by H-Score $<50$ & 1.27 & 0.57 & 2.82 & 0.561 \\
\hline Incidence of TNP by Allred Score & 1.09 & 0.47 & 2.57 & 0.836 \\
\hline
\end{tabular}

TNP — triple negative phenomenon; $\mathrm{Cl}$ - confidence interval

The absence of receptor expression was defined as 0 $[14,16,18]$. It should be noted that the results of the presented score differ greatly when converted to the $\mathrm{H}$-Score. Basing on the assumption that the result of below $10 \%$ of cells with positive weak or strong expression converted to the H-Score was between 10 and 30 and that all other cells did not show any expression, Voss et al. maintained that a H-Score below 150 translated to negative ER or PR expression [15].

In all the existing publications on endometrial cancer with TNP, the criteria for determining the HER2 receptor status were based on the standard adopted for breast cancer [27].

In this paper different criteria were adopted for the identification of a negative status of steroid receptors. Two scoring systems were used: $\mathrm{H}$-Score and Allred score.

The Allred score is generally employed to determine the status of steroid receptors in order to diagnose the triple negative breast cancer [28]. It seemed, therefore, appropriate to examine the criteria for diagnosing TNP in breast cancer in reference to endometrial cancer.

The H-Score was the most accurate scoring system for evaluating PR and ER expressions in digital image analysis which allowed for precise determination of the percentage of cells showing particular degrees of receptor expression. In this study a decision was made to adopt two thresholds when classifying expressions of steroid receptors by means of the $\mathrm{H}$-Score. The cut-off threshold of $<75$ stemmed from including all cases considered negative [22]. The cut-off threshold of $<50$ resulted from the assumption that the group was composed exclusively of the cases with negative status of steroid receptors [24]. It is worth noting that the above-mentioned criteria were applied to endometrial and breast cancer in the former case, while in the latter case — only to breast cancer [22-24].

When calculated according to the criteria quoted in the literature, the percentage of cancers with TNP ranged from $12 \%$ to $26 \%$. The discrepancies in results may have been caused by specific characteristics of the examined populations. Each study was conducted on a different continent. In a study covering the European population, the percentage of endometrial cancers with TNP was $12 \%$ [18]. In one publication, the percentage of endometrial cancers showing TNP was not determined [15]. In the present study the percentage of triple negative cancers ranged from $10.19 \%$ to $15.09 \%$. When adopting the criteria of diagnosis according to the Allrad score, the proportion of TNP was $10.19 \%$. In the case of the $\mathrm{H}$-Score $<50$ it reached $10.94 \%$, while according to the $\mathrm{H}$-Score $<75$ it was even higher at $15.09 \%$. If the criteria used most often in the literature were adopted, in the population under study the percentage of endometrial cancers with TNP would range between 5.24 and $8.61 \%$ $[14,16,18]$. When adopting the TNP diagnosis criteria proposed by Voss et al., the percentage of triple negative endometrial cancers would amount to $37.09 \%$. In view of vast 
discrepancies among the above outcomes, it is necessary to adopt unified criteria for the diagnosis of TNP, as in the case of triple negative breast cancer.

Breast cancer with TNP is burdened with poor prognosis [29]. Similar observations were made for triple negative ovarian cancer [30]. This type of cancer occurs more frequently in young patients and is characterized by an aggressive course. The present study found that the incidence of TNP was correlated with older age of patients at the time of diagnosis. Data concerning the age of patients diagnosed with endometrial cancer with TNP are contradictory.

The results of one study turned out to be consistent with the results of the present study, while other authors did not show such a correlation $[16,18]$. However, those authors revealed the relationship between poorer survivals of patients with TNP endometrial cancers. This relationship was not confirmed in this study, irrespective of the criteria used to diagnose TNP. It should be noted that shorter survival was correlated with the presence of TNP, regardless of the organ affected by the disease. It is worth noting, however, that the number of publications on survival in tumours of organs other than breast cancer is limited.

In this study, the system of digital image analysis was used to analyse the degree of expression of individual receptors, with the exception of the HER-2 receptor expression which was assessed manually according to the applicable criteria [27]. Significant subjectivity was observed in the assessment of receptor expression in the same histopathological preparation performed by several pathologists. In order to eliminate the above problem, programmes to count cells showing a positive response to the immunohistochemical staining reaction were developed. Endometrial cancer research has already used digital image analysis before $[31,32]$. For years numerous research teams have studied the variables relating to the morphology of cell nuclei in endometrial cancer [32, 33]. Paulik et al. [34], used digital image analysis to study the degree of PR and ER expressions and the cellular nucleus parameters in breast cancer.

\section{CONCLUSIONS}

The following conclusions were reached when verifying the research hypotheses put forward for the purpose of this study:

The percentage of TNP diagnosed in endometrial cancer depends on the population tested and the criteria adopted.

The survival of patients with endometrial cancer did not depend on the presence of TNP.

\section{Conflict of interests}

None.

\section{REFERENCES}

1. Bray F, Ferlay J, Soerjomataram I, et al. Global cancer statistics 2018 : GLOBOCAN estimates of incidence and mortality worldwide for 36 cancers in 185 countries. CA Cancer J Clin. 2018; 68(6): 394-424, doi: 10.3322/caac.21492, indexed in Pubmed: 30207593.

2. Torre LA, Bray F, Siegel RL, et al. Global cancer statistics, 2012. CA Cancer J Clin. 2015; 65(2): 87-108, doi: 10.3322/caac.21262, indexed in Pubmed: 25651787

3. Carlson MJ, Thiel KW, Leslie KK. Past, present, and future of hormonal therapy in recurrent endometrial cancer. Int J Womens Health. 2014; 6: 429-435, doi: 10.2147/IJWH.S40942, indexed in Pubmed: 24833920.

4. Zhang GY, Wu LY, Li B, et al. Retrospective analysis of prognostic variables and clinical outcomes in surgically staged intermediate risk endometrial carcinoma. Eur J Obstet Gynecol Reprod Biol. 2013; 169(2): 309-316, doi: 10.1016/j.ejogrb.2013.02.025, indexed in Pubmed: 23540792.

5. Trovik J, Wik E, Werner HMJ, et al. MoMaTEC study group. Hormone receptor loss in endometrial carcinoma curettage predicts lymph node metastasis and poor outcome in prospective multicentre trial. Eur J Cancer. 2013; 49(16): 3431-3441, doi: 10.1016/j.ejca.2013.06.016, indexed in Pubmed: 23932335.

6. Ramirez PT, Frumovitz M, Bodurka DC, et al. Hormonal therapy for the management of grade 1 endometrial adenocarcinoma: a literature review. Gynecol Oncol. 2004; 95(1): 133-138, doi: 10.1016/j. ygyno.2004.06.045, indexed in Pubmed: 15385122.

7. Wik E, Ræder MB, Krakstad C, et al. Lack of estrogen receptor-a is associated with epithelial-mesenchymal transition and PI3K alterations in endometrial carcinoma. Clin Cancer Res. 2013; 19(5): 1094-1105, doi: 10.1158/1078-0432.CCR-12-3039, indexed in Pubmed: 23319822.

8. Backes FJ, Walker CJ, Goodfellow PJ, et al. Estrogen receptor-alpha as a predictive biomarker in endometrioid endometrial cancer. Gynecol Oncol. 2016; 141(2): 312-317, doi: 10.1016/j.ygyno.2016.03.006, indexed in Pubmed: 26957478.

9. Dedes KJ, Wetterskog D, Ashworth A, et al. Emerging therapeutic targets in endometrial cancer. Nat Rev Clin Oncol. 2011; 8(5): 261-271, doi: 10.1038/nrclinonc.2010.216, indexed in Pubmed: 21221135.

10. Lapińska-Szumczyk S, Supernat A, Majewska H, et al. HER2-positive endometrial cancer subtype carries poor prognosis. Clin TransI Sci. 2014; 7(6): 482-488, doi: 10.1111/cts.12207, indexed in Pubmed: 25201050.

11. Kalogiannidis $I$, Petousis $S$, Bobos $M$, et al. HER-2/neu is an independent prognostic factor in type I endometrial adenocarcinoma. Arch Gynecol Obstet. 2014; 290(6): 1231-1237, doi: 10.1007/s00404-014-3333-2, indexed in Pubmed: 25022554.

12. Zhang $Y$, Zhao $D$, Gong $C$, et al. Prognostic role of hormone receptors in endometrial cancer: a systematic review and meta-analysis. World J Surg Oncol. 2015; 13: 208, doi: 10.1186/s12957-015-0619-1, indexed in Pubmed: 26108802.

13. Kumar $P$, Aggarwal R. An overview of triple-negative breast cancer. Arch Gynecol Obstet. 2016;293(2):247-269, doi: 10.1007/s00404-015-3859-y, indexed in Pubmed: 26341644.

14. Kothari R, Morrison C, Richardson D, et al. The prognostic significance of the triple negative phenotype in endometrial cancer. Gynecol Oncol. 2010; 118(2): 172-175, doi: 10.1016/j.ygyno.2010.04.015, indexed in Pubmed: 20605625.

15. Voss MA, Gordon N, Maloney S, et al. Tetraspanin CD151 is a novel prognostic marker in poor outcome endometrial cancer. Br J Cancer. 2011; 104(10): 1611-1618, doi: 10.1038/bjc.2011.80, indexed in Pubmed: 21505452.

16. Jiang XF, Tang QI, Shen XM, et al. Tumor-associated macrophages, epidermal growth factor receptor correlated with the triple negative phenotype in endometrial endometrioid adenocarcinoma. Pathol Res Pract. 2012; 208(12): 730-735, doi: 10.1016/j.prp.2012.09.011, indexed in Pubmed: 23122929.

17. Altundag $O$, Dursun $P$, Roach EC, et al. Triple negative endometrial cancer may be more sensitive to platinum based chemotherapy. J BUON. 2013; 18(1): 289, indexed in Pubmed: 23613418.

18. Porzio R, Cordini C, Rodolfi AM, et al. Triple negative endometrial cancer: Incidence and prognosis in a monoinstitutional series of 220 patients. Oncol Lett. 2020; 19(3): 2522-2526, doi: 10.3892/ol.2020.11329, indexed in Pubmed: 32194754.

19. Bulsa $M$, Urasińska E. Triple negative endometrial cancer. Ginekol Pol. 2017; 88(4): 212-214, doi: 10.5603/GP.a2017.0040, indexed in Pubmed: 28509323.

20. Graham AD, Faratian D, Rae F, et al. Tissue microarray technology in thee routine assessment of HER-2 status in invasive breast cancer: a prospec- 
tive study of the use of immunohistochemistry and fluorescence in situ hybridization. Histopathology. 2008; 52(7): 847-855, doi: 10.1111/j.136 5-2559.2008.03047.x, indexed in Pubmed: 18494613.

21. Voduc D, Kenney C, Nielsen TO. Tissue microarrays in clinical oncology. Semin Radiat Oncol. 2008; 18(2): 89-97, doi: 10.1016/j.semradonc.2007.10.006, indexed in Pubmed: 18314063.

22. McCarty KS, Miller LS, Cox EB, et al. Estrogen receptor analyses. Correlation of biochemical and immunohistochemical methods using monoclonal antireceptor antibodies. Arch Pathol Lab Med. 1985; 109(8): 716-721, indexed in Pubmed: 3893381.

23. Singh $\mathrm{M}$, Zaino RJ, Filiaci VJ, et al. Relationship of estrogen and progesterone receptors to clinical outcome in metastatic endometrial carcinoma: a Gynecologic Oncology Group Study. Gynecol Oncol. 2007; 106(2): 325-333, doi: 10.1016/j.ygyno.2007.03.042, indexed in Pubmed: 17532033.

24. Thike AA, Chng MJ, Fook-Chong S, et al. Immunohistochemical expression of hormone receptors in invasive breast carcinoma: correlation of results of H-score with pathological parameters. Pathology. 2001; 33(1): 21-25, indexed in Pubmed: 11280603.

25. Allred DC, Harvey JM, Berardo $M$, et al. Prognostic and predictive factors in breast cancer by immunohistochemical analysis. Mod Pathol. 1998; 11(2): 155-168, indexed in Pubmed: 9504686.

26. Gottwald L, Kubiak R, Pasz-Walczak G, et al. The value of progesterone and estrogen receptors expression in tissue microarray method in prognosis of patients with endometrioid endometrial cancer. Ginekol Pol. 2013; 84(2): 95-101, doi: 10.17772/gp/1547, indexed in Pubmed: 23668054.

27. Wolff $\mathrm{AC}$, Hammond $\mathrm{ME}$, Allison $\mathrm{KH}$, et al. Human epidermal growth factor receptor 2 testing in breast cancer: American Society of Clinical Oncology/College of American Pathologists Clinical Practice guideline focused update. J Clin Oncol. 2018; 36(20): 2105-2122, doi: 10.1200/JCO.2018.77.8738, indexed in Pubmed: 29846122.

28. Ryś-Bednarska $M$, Romanowicz $\mathrm{H}$. Potrójnie ujemny rak piers — diagnostyka i leczenie. Nowotwory Journal of Oncology. 2012; 62(6): 450-454.

29. Gonçalves H, Guerra MR, Duarte Cintra JR, et al. Survival study of triple-negative and non-triple-negative breast cancer in a Brazilian cohort. Clin Med Insights Oncol. 2018; 12: 1179554918790563 , doi: 10.1177/1179554918790563, indexed in Pubmed: 30083066.

30. Liu N, Wang X, Sheng X.,Triple negative'epithelial ovarian cancer and pathologic markers for prognosis. Curr Opin Obstet Gynecol. 2011; 23(1): 19-23, doi: 10.1097/GCO.0b013e32834252f5, indexed in Pubmed: 21150601.

31. Jagielski L, Jelen M, Kobierzycki C, et al. Increase of nuclear expression of metallothionein $\mathrm{I} / \mathrm{II}$ in neoplastic transformation of the endomnetrium. Ginekol Pol. 2015; 86(3): 182-187, doi: 10.17772/gp/2060, indexed in Pubmed: 25920307.

32. El-Sharkawy SL, Abbas NF, El-Henawy AMY, et al. Morphometric and DNA image analysis of endometrial hyperplasia and carcinoma. Appl Immunohistochem Mol Morphol. 2017; 25(1): 32-38, doi: 10.1097/PAl.0000000000000259, indexed in Pubmed: 26469331.

33. Miller J, Geisler JP, Manahan KJ, et al. Nuclear size, shape, and density in endometrial carcinoma: relationship to survival at over 5 years of follow-up. Does analyzing only cells occupying the G0-G1 peak add useful information? Int J Gynecol Cancer. 2004; 14(1): 138-144, doi: 10.1111/j.1048-891x.2004.14031.x, indexed in Pubmed: 14764042.

34. Paulik R, MicsikT, Kiszler G, et al. An optimized image analysis algorithm for detecting nuclear signals in digital whole slides for histopathology. Cytometry A. 2017; 91(6): 595-608, doi: 10.1002/cyto.a.23124, indexed in Pubmed: 28472544. 